\title{
Identification of Helicobacter in gastric biopsies by PCR based on 16S rDNA sequences: a matter of little significance for the prediction of H. pylori-associated gastritis?
}

\author{
ANNIKA TIVELJUNG, K. BORCH*, J. JONASSON, S. MÅRDH $\dagger$, F. PETERSSON $\ddagger$ \\ and H.-J. MONSTEIN \\ Divisions of Clinical Microbiology, * Surgery and $\uparrow$ Cell Biology, Faculty of Health Sciences, University of \\ Linköping and $¥$ Pathology Research Department, Ryhov Hospital, Jönköping, Sweden
}

\begin{abstract}
The aim of the present study was to correlate molecular evidence of the presence of Helicobacter pylori in gastric biopsy samples, based on analysis of 16S rDNA, vacuolating toxin (vacA), urease $\mathrm{A}$ (ure $A$ ) and $\operatorname{cag} A$ genes, with the clinical, histological and serological findings in patients with $H$. pylori-associated gastritis. Fresh biopsy samples were collected from the gastric antrum and corpus of 22 asymptomatic volunteers with or without $\boldsymbol{H}$. pylori-associated gastritis. Total DNA was extracted from the biopsy material and subjected to $16 \mathrm{~S}$ rDNA PCR amplification, Southern blotting and 16S rDNA sequence analysis of the PCR products. The vac $A$, ure $A$ and $\operatorname{cag} A$ genes were characterised by PCR amplification and Southern blot analysis. Based on partial $16 S$ rDNA sequence analysis, DNA belonging to the genus Helicobacter was detected in gastric biopsy samples from 20 of 22 subjects, including seven of nine histologically and serologically normal controls. Six of 20 partial $16 \mathrm{~S}$ rDNA sequences revealed variations within variable regions $\mathrm{V} 3$ and $\mathrm{V} 4$ that deviated from those of the $H$. pylori type strain ATCC $4350^{\mathrm{T}}$ and, therefore, possibly represented other species of Helicobacter. VacA genes identical with those of the type strain were found predominantly in the subjects with $H$. pylori gastritis, and all the patients except one were found to be cagA-positive. There was no evidence of false positive PCR reactions. In conclusion, the PCR-based molecular typing methods used here were apparently too sensitive when applied to the detection of $\boldsymbol{H}$. pylori in human gastric tissues. The lack of quantitative analysis makes them inappropriate as clinical tools for the diagnosis of $\boldsymbol{H}$. pylori-associated gastritis, despite the fact that they provide a qualitative and sensitive tool for the detection and characterisation of $\boldsymbol{H}$. pylori in the gastrointestinal tract.
\end{abstract}

\section{Introduction}

Helicobacter pylori is a micro-aerophilic gram-negative bacterium recognised as a human pathogen. It has been associated with chronic gastritis, peptic ulcer, gastric cancer and gastric mucosa-associated lymphoid tissue (MALT) lymphoma of the stomach [1]. The majority of $H$. pylori-infected individuals remain asymptomatic [2]. It has been suggested that subtypes of $H$. pylori might differ in pathogenicity [3]. Cytotoxin production (VacA) and the cytotoxin-associated gene protein

Received 13 Sept. 1997; revised version accepted 24 Dec. 1997.

Corresponding author: Dr H.-J. Monstein.
(CagA) [3, 4] are putative virulence factors. Accordingly, $H$. pylori strains have been classified into subgroups on the basis of $\operatorname{cag} A$ and $v a c A$ gene expression patterns [3], and different vacA signal sequences [5]. Several studies have revealed the presence of clonal variants in families with peptic ulcer disease [6-8]. Coccoid forms of H. pylori, not culturable in vitro, limit the use of bacterial culture for the investigation of biopsy material.

16S rDNA-based PCR methods have made it possible to detect non-culturable bacteria in human biopsy specimens [9-12]. Hoshina and co-workers identified H. pylori in gastric biopsy samples by PCR based on conserved and Helicobacter-specific 16S rDNA sequences [13]. Attempts have also been made to 
characterise $H$. pylori in gastric biopsy specimens by means of reverse-transcribed PCR (RT-PCR) directed towards 16S rDNA, cagA, ure A and ureC mRNA [14, 15]. Comparative and competitive PCR amplification analysis of gastric biopsy samples indicate that PCR amplification methods with isolated DNA are more reliable than reverse-transcribed RNA $[16,17]$.

Molecular typing methods have demonstrated considerable genomic diversity among $H$. pylori isolates. In a recent study, Georgopoulos and co-workers [6] used ribotyping to characterise $H$. pylori from patients with duodenal ulcer and their spouses. Randomly amplified polymorphic DNA (RAPD) analysis has also confirmed variability in the genome of $H$. pylori [18]. Kansau and co-workers [19] used another approach to compare RAPD analysis and urease $\mathrm{C}$ gene (ureC) sequence analysis and their results indicated that both methods gave satisfactory discrimination between strains. However, ureC DNA sequence analysis appeared to be more reliable and reproducible [19]. In a different study, DNA from cultured $H$. pylori isolates was analysed by restriction fragment length polymorphism (RFLP) of PCR-amplified products from the ure $A$ and $u r e B$ genes, and the results confirmed that ure $A$ and $u r e B$ PCR-RFLP provides a novel method of discriminating between $H$. pylori strains [20].

The aim of the present study was to establish molecular typing methods without bacterial culture, which will allow the direct detection, identification and characterisation of $H$. pylori and possibly also other Helicobacter species in human gastric tissues, by $16 \mathrm{~S}$ rRNA, vacA, ureA and cagA gene PCR amplification, Southern blot analysis and partial $16 \mathrm{~S}$ rDNA sequence analysis of PCR-amplified products. Furthermore, this study aimed to correlate molecular evidence of the presence of $H$. pylori in the biopsy material with clinical, histological and serological findings in selected patients with or without $H$. pylori-associated gastritis.

\section{Materials and methods}

\section{Study population}

The study was approved by the local ethics committee and conducted in accordance with the Helsinki Declaration, including informed written consent. The 22 individuals examined were selected, based on histological findings and rapid urease test, from a larger $(n=501)$ ongoing gastroscopic screening study in a randomly selected cohort of the population of Linköping, Sweden [21]. None of the subjects in the present study had sought medical advice for abdominal complaints. There were 10 men and 12 women with median age 56 years (range 44-79) and 60 years (range 43-76), respectively. Age did not differ significantly between men and women or between individuals with or without gastritis.

\section{Gastroscopy and biopsy}

Gastroscopy was performed after fasting overnight. Separately sterilised biopsy forceps were used for each location (corpus, antrum) in the stomach. Between gastroscopies, the forceps were treated in a Branson 3200 ultraware machine (Branson Europa BV). Both forceps and gastroscopes were washed for $30 \mathrm{~min}$ with EDT cleaner (ethoxybutylether 8-10\%, 1,2-propyleneglycol $30-50 \%$, proteolytic enzymes $0.5-2 \%$ and $\mathrm{Na}$ alkonsulphonate 3\%) (Olympus Optical AB) and disinfected for $5 \mathrm{~min}$ with EDT disinfectant (glutaraldehyde $20-22 \%$ and ethanol $7-10 \%$ ) in an Olympus Optical dishwasher for endoscopes. During gastroscopy, multiple biopsy specimens were collected from the corpus and antrum (within $3 \mathrm{~cm}$ of the pyloric ring) of the stomach. One biopsy specimen from each location was examined by rapid urease test (CLO test, Delta West Pty), three specimens were oriented and fixed in buffered formalin $4 \%$ and five specimens were quick frozen in liquid nitrogen and stored at $-80^{\circ} \mathrm{C}$ until analysed. A change in colour $(\mathrm{pH})$ in the rapid urease test within $12 \mathrm{~h}$ of placing the biopsy in the medium was regarded as indicative of the presence of $H$. pylori. After routine processing of the formalin-fixed biopsy samples, $4-\mu \mathrm{m}$ thick sections cut perpendicular to the mucosal surface were stained with haematoxylin-eosin, Alcian blue/periodic acid-Schiff and Giemsa stain. Gastritis was classified microscopically according to the Sydney system [22, 23], including semi-quantification of the number of $H$. pylori and coccoid bacteria present on the mucosal surface or in the crypts.

Histologically, there were 13 cases with chronic gastritis and nine cases with normal morphology and without $H$. pylori in the antrum or corpus. The histological findings are summarised in Table 1. Of the 13 subjects with gastritis, one had antrum predominant (type B) gastritis with atrophy, 10 had pangastritis (type $A B$ ) (three with atrophy), and two had corpus predominant (type A) gastritis (one with atrophy).

\section{Serological analysis}

H. pylori antibodies in serum were analysed by an enzyme-linked immunosorbent assay (ELISA), as described previously (upper normal limit 5.0\% of positive standard) [24]. Serological findings are summarised in Table 1 .

\section{Bacterial strain}

H. pylori CCUG $17874^{\mathrm{T}}$ (ATCC $43504^{\mathrm{T}}$, obtained from the Culture Collection of the University of Gothenburg, Sweden) was used as a reference strain. 


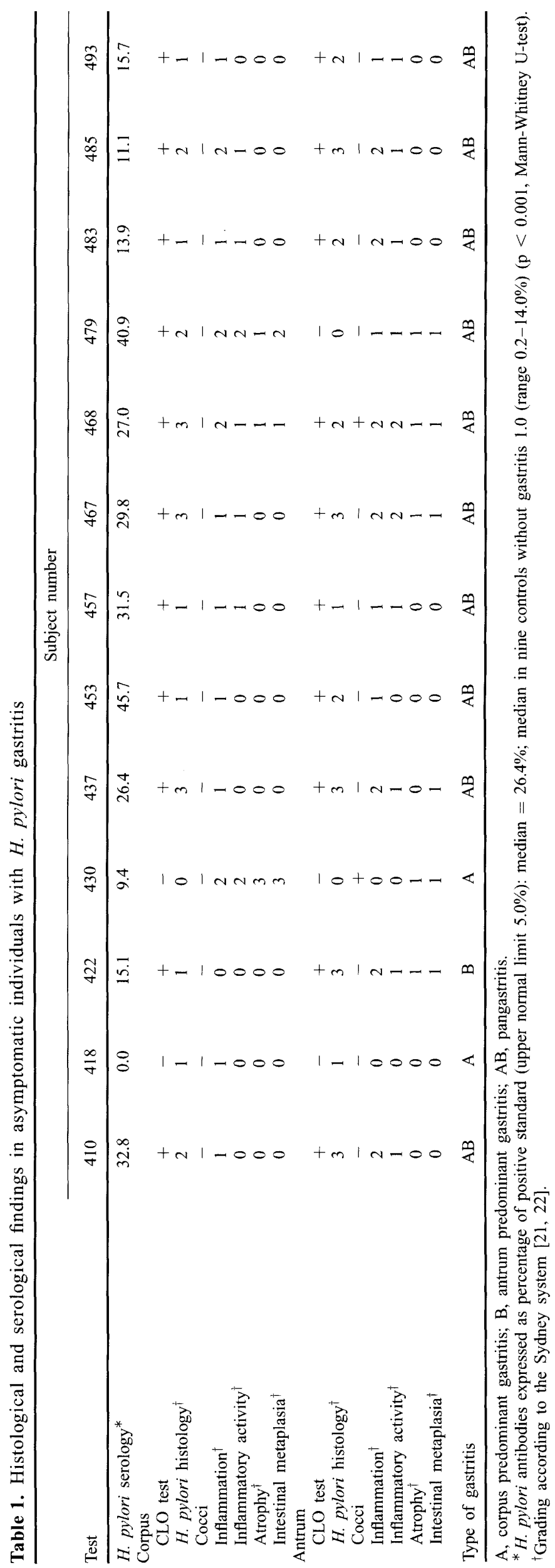




\section{Preparation of samples for PCR amplification}

Bacterial genomic DNA from the reference strain $H$. pylori CCUG $17874^{\mathrm{T}}$ was extracted as described previously [11]. Total DNA from the human gastric biopsy specimens was prepared by extraction with the Trizol reagent-chloroform system (Gibco BRL, Life Technologies). The extraction procedure followed the manufacturer's recommendations. Briefly, the biopsy specimen (c. $5 \mathrm{mg}$ ) was homogenised mechanically (Polytron, Kinematica) in $0.5 \mathrm{ml}$ of phenol-based Trizol reagent. The homogenate was mixed with chloroform and, after centrifugation, DNA was recovered from the phenol phase by ethanol precipitation. DNA concentration and purity were measured spectrophotometrically at $\mathrm{OD}_{260}$ and $\mathrm{OD}_{280}$, respectively. To exclude any possible contamination from the homogeniser, a negative control containing only the Trizol reagent was run in parallel and examined by PCR and Southern blot analysis of the PCR-amplified products.

\section{Oligonucleotides}

PCR primers were obtained from Pharmacia Biotech (Pharmacia). The 16S rDNA broad-range bacterial primers $\mathrm{pJB}-1$ and $\mathrm{p} 13 \mathrm{~B}$ have been described previously [11]. Two Helicobacter-specific primers were designed from the variable regions V4 (HPV4) and V9 (HPV9) within the 16S rRNA gene [25]. HPV9 was used as a DNA sequencing primer and HPV4 was used as a hybridisation probe (Table 2). PCR primers and DNA hybridisation probes, directed against putative $H$. pylori virulence genes, were complementary to the urease A gene (ure $A$ ), the vacuolating toxin gene $(\operatorname{vac} A)$ and the cytotoxin-associated $(\operatorname{cag} A)$ gene sequences, respectively (Table 2). All primer combinations were tested in PCR amplification under the conditions described below, with human genomic DNA, to rule out any non-specific amplification.

\section{PCR conditions}

Amplifications were performed in a final volume of $50 \mu \mathrm{l}$ containing $2 \mu \mathrm{M}$ primer, $0.2 \mathrm{mM}$ deoxyribonucleotide (dGTP, dATP, dTTP and dCTP; Boehringer-Mannheim), reaction buffer $(100 \mathrm{mM}$ Tris$\mathrm{HCl}, 500 \mathrm{mM} \mathrm{KCl}, 15 \mathrm{mM} \mathrm{MgCl}_{2} ; \mathrm{pH} \mathrm{9.0),} \mathrm{and} 0.25 \mathrm{U}$ of Taq polymerase (Pharmacia). Approximately $100 \mathrm{ng}$ of total DNA were used for bacterial broad-range $16 \mathrm{~S}$ rDNA, ureA, vacA and $\operatorname{cag} A$ amplification, respectively. PCR was performed in thin-walled $0.5-\mathrm{ml}$ GeneAmp reaction tubes (Perkin Elmer), in a Minicycler PT-150 (SDS Promega) as follows: denaturation at $94^{\circ} \mathrm{C}$ for $30 \mathrm{~s}$, annealing at $55^{\circ} \mathrm{C}$ for $30 \mathrm{~s}$, extension at $72^{\circ} \mathrm{C}$ for $1 \mathrm{~min}$ (30 cycles) and a final extension at $72^{\circ} \mathrm{C}$ for $10 \mathrm{~min}$. Expected fragment sizes of the PCR amplified products are $c .450 \mathrm{bp}$ for $16 \mathrm{~S}$ rDNA, $c$. $680 \mathrm{bp}$ for $v a c A, c .420 \mathrm{bp}$ for $u r e A$ and $c .350 \mathrm{bp}$ for $\operatorname{cag} A$. Negative PCR controls, containing only buffer and PCR primers, were run in parallel.

\section{Detection and analysis of amplified PCR products}

Broad-range $16 \mathrm{~S}$ rDNA amplified PCR products were analysed by agarose gel electrophoresis and Southern blot analysis. PCR-amplified products were electrophoresed on an agarose $1.5 \%$ gel, stained with ethidium bromide and visualised under UV light. Broad-range 16S rDNA PCR products were transferred to Hybond-N membranes and hybridised to a Helicobacter-specific HPV4 probe, which was $5^{\prime}$ end-labelled with $\left[\gamma_{-}{ }^{32} \mathrm{P}\right]$ dATP $(3000 \mathrm{Ci} / \mathrm{mmol}$ Amersham $)$ $\left(1 \mathrm{Ci}=3.7 \times 10^{10} \mathrm{~Bq}\right)$ and a $5^{\prime}$ end-labelling kit (Boehringer-Mannheim). Prehybridisation and hybridisation with the HPV4 probe were carried out in SEPbuffer $\left(0.5 \mathrm{M} \mathrm{Na}_{2} \mathrm{PO}_{4}, \mathrm{pH} 7.2,1 \mathrm{mM}\right.$ EDTA-sodium salt; $\operatorname{SDS} 7 \%$ ) at $50^{\circ} \mathrm{C}$ overnight. Filters were washed in $1 \times \mathrm{SSC} / \mathrm{SDS} 0.1 \%$ for $3 \times 20 \mathrm{~min}(1 \times \mathrm{SSC}=$ $150 \mathrm{mM} \mathrm{NaCl}, 15 \mathrm{mM}$ sodium citrate). After the posthybridisation step, membranes were exposed to Amer-

Table 2. Oligonucleotide primers used in PCR amplification, Southern blot, and DNA sequence analysis

\begin{tabular}{|c|c|c|c|c|}
\hline Primer name & Start position in & H. pylori DNA & DNA sequence $\left(5^{\prime}-3^{\prime}\right.$ orientation $)$ & $\begin{array}{l}\text { Accession number } \\
\text { Genebank/EMBL }\end{array}$ \\
\hline pJB-I ${ }^{* \ddagger}$ & $959^{\$}$ & $\rightarrow$ & ATTCGATGCAACGCGAAGAACCTTACC & $\ldots$ \\
\hline p13B* & $1397^{\S}$ & $\leftarrow$ & GTGTACTAGGCCCGGGAACGTATTC & $\cdots$ \\
\hline HPV4 ${ }^{\dagger}$ & $1175^{\$}$ & $\leftarrow$ & CCTCCTTACGGAGGCAGTATCCTT & $\ldots$ \\
\hline HPV $9^{*}$ & $1259^{\sharp}$ & $\leftarrow$ & GCTTCTCTTTGTGCACCCCAT & $\ldots$ \\
\hline ureA- $1^{*}$ & $2818^{\|}$ & $\rightarrow$ & GCGGCTGAATTGATGCAAGAAGG & M60398 \\
\hline ureA- $2^{\dagger}$ & $3014^{\|}$ & $\rightarrow$ & CTATCAACGAAGGCAAAAAAGCCG & M60398 \\
\hline ureA- $3^{*}$ & $3230^{\|}$ & $\leftarrow$ & CCGCCAATGTCAATCAATTCTACGG & M60398 \\
\hline $\operatorname{vacA}-1^{*}$ & $828 \|$ & $\rightarrow$ & CAATCGTGTGGGTTCTGGAGC & S72494 \\
\hline $\operatorname{vacA}-2^{\dagger}$ & 1337 & $\leftarrow$ & CTATTGGGTGGGTTAATGACCTGAG & S72494 \\
\hline $\operatorname{vacA}-3^{*}$ & 1506 & $\leftarrow$ & GCCGATATGCAAATGAGCCGC & $\mathrm{S} 72494$ \\
\hline $\operatorname{cagA}-1^{*}$ & $691^{\|}$ & $\rightarrow$ & GATAACAGGCAAGCTTTTGAGGG & $\times 70039$ \\
\hline $\operatorname{cag} A-2^{\dagger}$ & $864 \|$ & $\rightarrow$ & GAAATTTGGGGATCAGCGTTACC & X70039 \\
\hline $\operatorname{cagA}-3^{*}$ & $1041^{\|}$ & $\leftarrow$ & TCCTGCAAAAGATTGTTTGGCAGA & X70039 \\
\hline
\end{tabular}

$(\rightarrow)$ sense; $(\leftarrow)$ antisense direction of PCR primers and DNA hybridisation probes.

${ }^{*}$ PCR amplificaiton primer.

${ }^{\ddagger}$ DNA hybridisation probe used in Southern blot analysis of PCR amplified products.

${ }^{\ddagger}$ DNA sequencing primer.

Positions according to Gray et al. [25].

Positions according to referred accession. numbers. 
sham MP X-ray films at low temperature $\left(-70^{\circ} \mathrm{C}\right)$ for 3-6 days. The ureA, vacA and cagA PCR-amplified products were analysed by agarose gel electrophoresis and Southern blot analysis, followed by hybridisation with ure $A-2, \quad v a c A-2$ and $\operatorname{cag} A-2 \quad 5^{\prime}$ end-labelled hybridisation probes as described above. Hybridisations were performed as described earlier, except that posthybridisation washing was in $2 \times \mathrm{SSC} / \mathrm{SDS} 0.1 \%$.

\section{DNA sequencing}

16S rDNA PCR amplified products were sequenced directly with an Fmol Cycle Sequencing kit (SDS Promega). The Helicobacter-specific primer HPV9 and the broad range primer pJB-1 were used in DNA sequence analysis. Cycle parameters were as follows: denaturation at $94^{\circ} \mathrm{C}$ for $20 \mathrm{~s}$, annealing at $60^{\circ} \mathrm{C}$ for $20 \mathrm{~s}$ and extension at $70^{\circ} \mathrm{C}$ for $30 \mathrm{~s}$ ( 30 cycles). Exposed X-ray films were subsequently analysed with a computerised film scanner (SciScan 5000, Basescanner software, United States Biochemical, Amersham). Comparative DNA sequence analysis with DNA databanks (EMBL and GeneBank) was performed.

\section{Results}

Identification of Helicobacter by PCR based on 16S rDNA sequences

Bacterial DNA was detected in c. $5 \mathrm{mg}$ of gastric biopsy specimens. One antral and one corpus biopsy specimen from each individual were used in broadrange 16S rDNA PCR analysis. The results (Table 3) are presented at an individual level, not focusing on whether colonisation occurred in the antrum, corpus or both. In all biopsy specimens examined, a single $16 \mathrm{~S}$ rDNA PCR-amplified product of $c .450 \mathrm{bp}$ was detected on the ethidium bromide-stained agarose gel (data not shown). Thus, eubacteria of unknown identity were demonstrated in all 22 individuals (both gastritis and normal control groups). To verify the presence of Helicobacter in the biopsy specimens, PCR-amplified products were analysed by Southern blot analysis with a Helicobacter-specific $5^{\prime}$ end-labelled probe, HPV4 (Table 2) which revealed the presence of Helicobacter in 17 of 22 biopsy specimens (12 from the gastritis group, the exception was No. 418 , and five from the normal control group, Nos. 344, 436, 450, 484 and 492).

All results were obtained from at least two experiments on the same biopsy specimen, yielding identical results except in two cases (biopsy specimens from subjects 454 and 456 ).

Contamination controls were run in parallel. All controls were negative, indicating reliable DNA extraction and PCR amplification procedures.

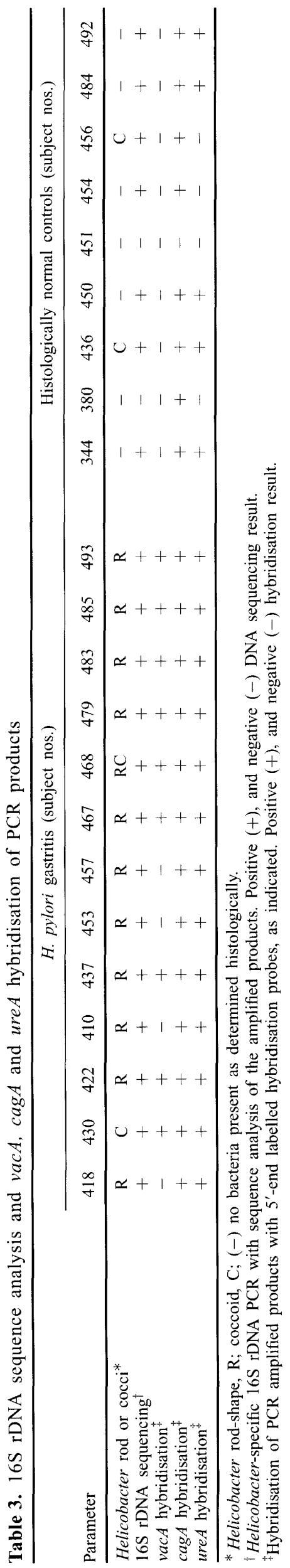




\section{Partial $16 S$ rDNA sequence analysis of DNA isolates}

To assess possible DNA sequence diversity among different Helicobacter strains, 16S rDNA broad-range PCR-amplified products were sequenced in both directions. DNA sequence analysis turned out to be more sensitive than the Southern blot analysis and revealed the presence of Helicobacter in 20 of 22 subjects (Table 3). The partial 16S rDNA sequences from 14 subjects were identical to $H$. pylori type strain CCUG $17874^{\mathrm{T}}$ (Fig. 1). However, six sequences deviated from that of the type strain in either of the variable regions V3 and V4, or both. Partial 16S rDNA sequences from subject nos. 422,457 and 467 with gastritis were identical, showing two base shifts in the variable region V3 at locations 1030 and 1037 , respectively (Fig. 1a). The $16 \mathrm{~S}$ rDNA sequence from subject no. 479 (gastritis) showed the same variations in region $\mathrm{V} 3$ as the above-mentioned subjects, whereas subject no. 410 (gastritis) showed a base shift at location 1008. The 16S rDNA sequence from subject no. 453 (gastritis) was identical with the type strain in the variable region $\mathrm{V} 3$, whereas the $16 \mathrm{~S} \mathrm{rDNA}$ sequence deviated from the type strain in the variable region V4 at position 1136 (Fig. 1b). The $16 \mathrm{~S}$ rDNA sequence from subject no. 479 (gastritis) showed two base shifts in positions 1151 and 1154 , respectively (Fig. 1b). All other strains were identical with the type strain in this region.

The deviating strains were all found in biopsy samples from subjects with antral gastritis or pangastritis. Only $H$. pylori-identical strains were identified in the Helicobacter-positive normal control group.

\section{Characterisation of virulence factor genotype}

The screening of Helicobacter-positive samples for ure $A, v a c A$ and $\operatorname{cag} A$ genotypes (identical to $H$. pylori type strain) revealed that these genotypes were more frequent in subjects with $H$. pylori gastritis than in the normal controls (Table 3). Biopsy samples from individuals with gastritis harboured $\mathrm{ureA}^{+} / \mathrm{cag} A^{+}$ Helicobacter strains. In this group, all individuals, except nos. 410, 418, 453 and 457, displayed a $H$. pylori type strain-identical $v a c A^{+}$genotype. Among subjects in the normal control group shown to be Helicobacter-positive, the $u r e A^{+} / \mathrm{cag} A^{+}$genotype was found in nos. 344, 436, 450, 484 and 492 . Subjects 454 and 456 displayed only a $c a g A^{+}$genotype. The type strain-identical vacA genotype was not identified in biopsy samples from individuals in the normal control group. The virulence genes $\operatorname{cag} A$ and ure $A$ demonstrated in these normal controls support the results of 16S rDNA analysis, which makes the possibility of a false positive result due to contamination with PCR products unlikely.

The primer combinations used here were also tested on isolated human genomic DNA. No visible PCR amplification products were detected on ethidium bromide-stained gels, demonstrating the bacterial DNA specificity of the primer combinations used (data not shown).

\section{Comparison between 16S rDNA analysis, histology, rapid urease test and serology}

The results of serology, histological examinations and rapid urease tests were in good agreement (Table 1). Histological examination of one subject with atrophic corpus gastritis (no. 430) revealed the absence of colonising rod-shaped $H$. pylori, but undefined coccoid cells were recognised; 16S rDNA analysis demonstrated the presence of Helicobacter. In the normal control group, two subjects (nos. 436 and 456) harboured undefined coccoid cells, which were confirmed as Helicobacter by $16 \mathrm{~S}$ rDNA analysis. Among the nine histologically defined normal controls, 16S rDNA analysis revealed seven Helicobacter-positive cases (Table 3). In the gastritis group, 11 of 13 subjects colonised by Helicobacter were urease-positive. Subjects 418 and 430 were urease-negative, but $16 \mathrm{~S}$ rDNA analysis revealed Helicobacter. 16S rDNA analysis and serology were in agreement in the gastritis group except in one case (no. 418) which was serum negative. Among the normal controls, serology detected one Helicobacter-positive subject (no. 454), whereas 16S rDNA analysis revealed Helicobacter in seven cases.

\section{Discussion}

This study isolated total DNA from gastric biopsy specimens from 22 asymptomatic individuals and verified the presence of nucleotide sequences corresponding to the genus Helicobacter in 20 of them by $16 \mathrm{~S}$ rDNA, vacA, cagA and ure $A$ gene analysis. It is believed generally that only Helicobacter colonise the stomach. However, the broad-range 16S rDNA PCR combined with Southern blot analysis of the PCRamplified products showed that other bacterial species may be present in these specimens. It can be speculated that this is due to contamination with bacteria in swallowed saliva or respiratory secretions; however, other explanations are also possible. A recent study revealed that the commercially available Taq DNA polymerases contain minute amounts of DNA [28]. As a highly sensitive PCR assay (30 cycles, see ref. 28 ) was used in the present study, the possibility that part of the non-helicobacter-specific DNA may be due to contaminating DNA in the commercial Taq DNA polymerase used cannot be excluded. Another explanation might be that other bacteria colonise the gastric mucosa, as Kabir and co-workers showed in a recent study with a gnotobiotic murine model [29]. Helicobacter DNA was also found in seven of nine individuals without gastritis (characterised as $H$. pylori-negative by urease test, histology and serology). This discrepancy may be due either to the high 
v3

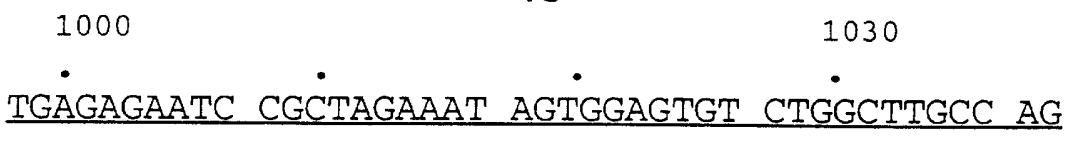

\section{H. pylori CCUG $17874^{\mathrm{T}}$}

a Identical to type strain ${ }^{1}$

410

422

453

457

467

479

b H. pylori MC903

H. pylori MC937

c H. rappini ATCC 43879

H. cinaedi CCUG $18818^{\mathrm{T}}$

H. fennelliae CCUG $18820^{\mathrm{T}}$

$H$. heilmannii isolate 2

H. acinonyx CCUG $29263^{\mathrm{T}}$

H. nemestrinae ATCC $49396^{\mathrm{T}}$

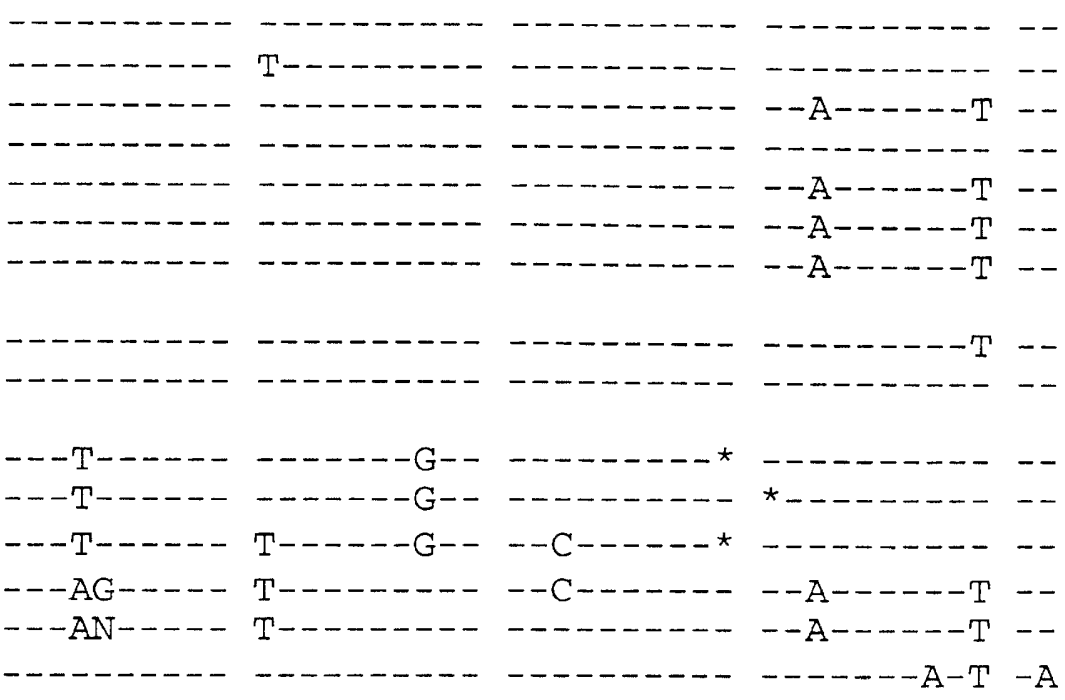

1120

V4

1150

H. pylori CCUG $17874^{\mathrm{T}}$

TTTCTTAGTT GCTAACAGGT CATGCTGAGA ACTCTAAGGA TA

a Identical to type strain ${ }^{1}$

410

422

453

457

467

479

b H. pylori MC903

H. pylori MC937

H. pylori MC123

c H. rappini ATCC 43879

H. cinaedi CCUG $18818^{\mathrm{T}}$

H. fennelliae CCUG $18820^{\mathrm{T}}$

H. heilmannii isolate 2

H. acinonyx CCUG $29263^{\mathrm{T}}$

H. nemestrinae ATCC $49396^{\mathrm{T}}$

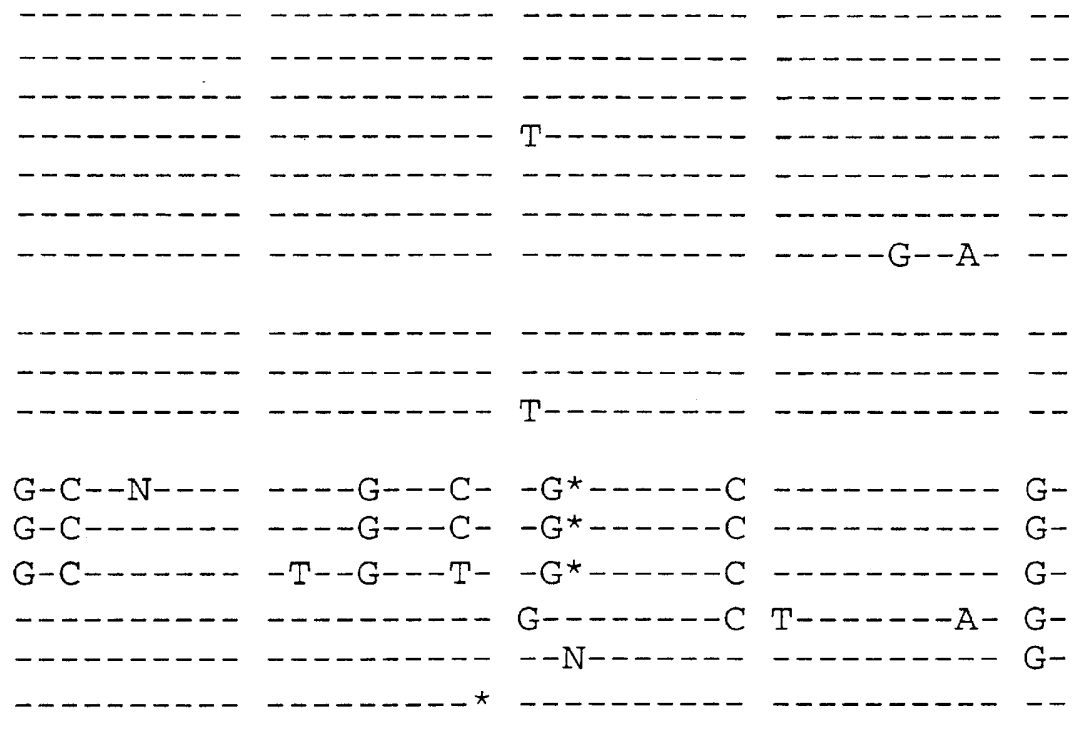

Fig. 1. Partial 16S rDNA sequences from variable regions V3 (A) and V4 (B), respectively (underlined): a, from 20 biopsy samples that were identical to the type strain ${ }^{1}$ including subject nos. 344, 418, 430, 436, 437, 450, 454, 456, $468,483,484,485,492$ and 493; b, from $H$. pylori - isolates as previously published [26]; c, from related Helicobacter species known to colonise the gastro-intestinal tract of primates [27]. The 16S rDNA sequence from $H$. heilmannii isolate 2 was retrieved from Genebank/EMBL, accession number L10080. (-) denotes identical sequence to type strain, $\left(^{*}\right)$ denotes deletions.

sensitivity of the broad-range 16S rRNA gene PCR combined with DNA sequence analysis, or to contamination of biopsy samples. Contamination by means of transfer of bacteria with forceps or the gastroscope from one patient to another seems unlikely (see disinfection procedures). Instead, the present data indicate that minute amounts of $H$. pylori DNA are nearly always present in gastric biopsy samples. 
Provided that a significant fraction of H. pyloriinfected individuals do not develop gastritis or circulating antibodies and that all six histologically examined biopsy samples (three corpus and three antrum biopsy samples from each subject) in each of seven normal controls (total of 42 biopsies) were taken in non-colonised areas (morphologically defined), a minor patchy colonisation pattern of $H$. pylori could have contributed to the discrepancies observed. The small size of gastric biopsy specimens, when only minor colonisation exists, may result in colonised and non-colonised biopsy specimens [16]. Unlike bacterial culture methods, most PCR techniques do not allow quantitative analysis; therefore, multiple analysis of the individual biopsy samples may help to overcome this problem. An advantage of PCRbased detection of Helicobacter is that non-culturable Helicobacter strains, either rod-shaped or coccoid forms can be detected by PCR amplification techniques. This fact became obvious in the analysis of normal controls, where it was found that seven of nine subjects harboured Helicobacter 'species'. Similar results have been reported by Hoshina and co-workers [13] and Lage and co-workers [17]. These investigators detected $H$. pylori and related helicobacters by means of DNA-based PCR in culture-, histology- and rapid urease test-negative biopsy specimens. However, in the study by Peek et al. [14], reverse-transcribed rather than DNA-based PCR was used. Peek et al. [14] did not compare 16S rDNA and ureA genotypes (DNA-based PCR) and the phenotypes (RT-PCR), which makes it difficult to evaluate their RT-PCR negative results. Low transcriptional activity, short half-life and degradation of bacterial mRNA and builtin errors in the RT-PCR technique [30] may explain the failure of Peek et al. [14] to detect all H. pyloripositive biopsy samples by RT-PCR.

The cagA genotype, which is associated with peptic ulcer disease, was found in biopsy samples from almost all subjects, including those without gastritis, which would render them potential candidates for ulcer development [5]. However, ulcer disease is generally not observed in the absence of gastritis. Previously, $\operatorname{cag} A$ genotypes have been reported to be present in c. $80 \%$ of clinical isolates [3], which is different from the results in the present study. On the other hand, the latter results agree with a study by Miehlke and co-workers who reported that in patients from Korea and Houston $\operatorname{cag} A$ appeared to be present in a high proportion of $H$. pylori isolates $(98.3 \%$ and $88 \%$, respectively) [31]. The $\operatorname{cag} A^{+}$result in an otherwise Helicobacter-negative normal control (no. 380 ) is difficult to explain. It is unlikely that this was caused by contamination with PCR product from another reaction. The same result has been obtained repeatedly.

The vacA genotype in this study is correlated with the H. pylori type strain CCUG $17874^{\mathrm{T}}$ [32]. The PCR primers used were designed to cover the mid-region of the vacA gene where deletions are observed in noncytotoxin (tox ${ }^{-}$) and type strain-like cytotoxin-producing strains, respectively [33]. The hybridisation probe detected $v a c A^{+}$type strain-identical $v a c A$ genotypes. All $v a c A^{+}$isolates were identified among the subjects with $H$. pylori gastritis. In the normal control group all individuals harbouring $H$. pylori were vac $A^{-}$. The possibility that these $H$. pylori strains are less pathogenic than the $H$. pylori type strain ATCC 43504 cannot be excluded.

The ureA genotype was expected to be present in all Helicobacter-positive strains. However, the study was unable to detect the ure $A$ gene in two histologically normal controls, which were positive for $H$. pylori by 16S rDNA analysis and $\operatorname{cag} A^{+}$(nos. 454 and 456). Tsuda and co-workers [34] showed that a ureasenegative $H$. pylori mutant (rod-shaped) was unable to colonise the antrum of nude mouse mucosa. In contrast, Shen and co-workers [35] recently described the isolation of a new, urease-negative Helicobacter ( $H$. rodentium). The possibility that a similar Helicobacter species was present among the human normal controls in the present study has not been ruled out. Although clinical isolates of $H$. pylori are generally urease positive, spontaneously arising urease-negative strains of $H$. pylori have been reported [36, 37]. Based on these findings, the urease-negative $H$. pylori in the normal control group cannot simply be treated as an artefact.

Partial 16S rDNA analysis revealed that six of 22 individuals harboured Helicobacter strains that differed from the $H$. pylori type strain in the variable regions V3 and V4 [25]. Thus, based on their different 16S rDNA sequences, two groups of Helicobacter could be detected in individuals with asymptomatic $H$. pylori gastritis - the type strain-identical group and a non-identical $H$. pylori group, respectively. These findings might indicate that different strains are associated with different types of gastritis, or inflammatory response, or both; but the clinical significance of $16 \mathrm{~S}$ rDNA sequence variation remains unresolved. Admittedly, the present study only sequenced c. 250 bases of the whole 16S rDNA gene, covering two variable regions. However, initially PCR products were sequenced in duplicate yielding the same DNA sequence variations and, therefore, it is our opinion that the reported base variations are not the result of PCR artifacts. Moreover, these results are in agreement with previous findings where similar DNA sequence variations in the $16 \mathrm{~S}$ rRNA gene from Helicobacter have been reported [26]. Comparison of the variants identified by us and others [26] with related Helicobacter species, known to colonise the human gastrointestinal tract, demonstrates an obvious relationship to the genus Helicobacter (Fig. 1). The taxonomy of these $H$. pylori-like strains may be a matter of debate. Subdivision of the species $H$. pylori 
into subspecies, based on bioptypes, pathotypes or serotypes for taxonomic as well as clinical reasons has been suggested recently [38]. If such $H$. pylori pathotypes exist, it may help to explain the results obtained from $H$. pylori isolates found in the normal control subjects of this study (see above). 16S rDNA sequences may not always be sufficient to allow taxonomic distinction between species or subspecies [39]. However, the partial $16 \mathrm{~S}$ rDNA sequence data combined with the ureA, $\operatorname{cag} A$ and $v a c A$ patterns do support H. pylori subdivision [38].

The highly sensitive PCR-based molecular typing methods described here detect $H$. pylori in human gastritis biopsy samples. The PCR-based results are in good agreement with the results of morphology and serology. In contrast, different results were obtained with these methods in the analysis of human gastric biopsy samples from morphologically and serologically defined $H$. pylori-negative normal controls. Therefore, it may be argued that the overall application of molecular typing methods to identify $H$. pylori is not always appropriate, and thus may not replace commonly used typing and detection methods for patients with gastritis. On the other hand, these molecular typing methods are sensitive and discriminating enough to detect Helicobacter in human tissues from other areas of the gastrointestinal tract.

This study was supported by the Molecular Biology Program, LMÖ, University Hospital, Linköping, Sweden and grants from the Swedish National Cancer Association and the Swedish Medical Research Council. A. T. was supported by a Faculty Doctoral Fellowship from the Faculty of Health Sciences, University of Linköping, Sweden.

\section{References}

1. McGowan CC, Cover TL, Blaser MJ. Helicobacter pylori and gastric acid: biological and therapeutic implications. Gastroenterology 1996; 110: 926-938.

2. Dooley $\mathrm{CP}$, Cohen H, Fitzgibbons PL et al. Prevalence of Helicobacter pylori infection and histologic gastritis in asymptomatic persons. $N$ Engl J Med 1989; 321: 1562-1566.

3. Xiang Z, Censini S, Bayeli PF et al. Analysis of expression of CagA and VacA virulence factors in 43 strains of Helicobacter pylori reveals that clinical isolates can be divided into two major types and that CagA is not necessary for expression of the vacuolating cytotoxin. Infect Immun 1995; 63: 94-98.

4. Cover TL, Tummuru MKR, Cao P, Thompson SA, Blaser MJ Divergence of genetic sequences for the vacuolating cytotoxin among Helicobacter pylori strains. J Biol Chem 1994; 269: $10566-10573$.

5. Atherton JC, Peek RM, Tham KT, Cover TL, Blaser MJ Clinical and pathological importance of heterogeneity in vacA the vacuolating cytotoxin gene of Helicobacter pylori. Gastroenterology 1997; 112: 92-99.

6. Georgopoulos SD, Mentis AF, Spiliadis CA et al. Helicobacter pylori infection in spouses of patients with duodenal ulcers and comparison of ribosomal RNA gene patterns. Gut 1996; 39: 634-638.

7. Nwokolo CU, Bickley J, Attard AR, Owen RJ, Costas M, Fraser IA. Evidence of clonal variants of Helicobacter pylori in three generations of duodenal ulcer disease family. Gut 1992; 33: 1323-1327.

8. van der Ende A, Rauws EAJ, Feller M, Mulder CJJ, Tytgat GNJ, Dankert J. Heterogenous Helicobacter pylori isolates from members of a family with a history of peptic ulcer disease. Gastroenterology 1996; 111: 638-647.
9. Relman DA, Schmidt TM, MacDermott RP, Falkow S. Identification of the uncultured bacillus of Whipple's disease. $N$ Engl J Med 1992; 327: 293-301.

10. Monstein H-J, Kihlström E, Tiveljung A. Detection and identification of bacteria using in-house broad range $16 \mathrm{~S}$ rDNA PCR amplification and genus-specific DNA hybridization probes, located within variable regions of $16 \mathrm{~S}$ rRNA genes. APMIS 1996; 104: 451-458.

11. Tiveljung A, Backström J, Forsum U, Monstein H-J. Broadrange PCR amplification and DNA sequence analysis reveals variable motifs in $16 \mathrm{~S}$ rRNA genes of Mobiluncus species. APMIS 1995; 103: 755-763.

12. Tiveljung A, Forsum U, Monstein HJ. Classification of the genus Mobiluncus based on comparative partial 16S rRNA gene analysis. Int $J$ Syst Bacteriol 1996; 46: 332-336.

13. Hoshina S, Kahn SM, Jiang W et al. Direct detection and amplification of Helicobacter pylori ribosomal $16 \mathrm{~S}$ gene segments from gastric endoscopic biopsies. Diagn Microbiol Infect Dis 1990; 13: 473-479.

14. Peek RM, Miller GG, Tham KT et al. Detection of Helicobacter pylori gene expression in human gastric mucosa. $J$ Clin Microbiol 1995; 33: 28-32.

15. van Zwet AA, Thijs JC, Kooistra-Smid AMD, Schirm J, Snijder JAM. Sensitivity of culture compared with that of polymerase chain reaction for detection of Helicobacter pylori from antral gastric biopsy samples. J Clin Microbiol 1993; 31: 1918-1920.

16. Furuta T, Kaneko E, Suzuki M, Arai H, Futami H. Quantitative study of Helicobacter pylori in gastric mucus by competitive PCR using synthetic DNA fragments. J Clin Microbiol 1996; 34: $2421-2425$.

17. Lage AP, Godfroid E, Fauconnier A et al. Diagnosis of Helicobacter pylori infection by PCR: comparison with other invasive techniques and detection of cagA gene in gastric biopsy specimens. J Clin Microbiol 1995; 33: 2752-2756.

18. Akopyanz N, Bukanov NO, Westblom TU, Kresovich S, Berg DE. DNA diversity among clinical isolates of Helicobacter pylori detected by PCR-based RAPD fingerprinting. Nucleic Acids Res 1992; 20: 5137-5142.

19. Kansau I, Raymong J, Bingen E et al. Genotyping of Helicobacter pylori isolates by sequencing of PCR products and comparison with the RAPD technique. Res Microbiol 1996; 147: 661-669.

20. Lopez CR, Owen RJ, Desai M. Differentiation between isolates of Helicobacter pylori by PCR-RFLP analysis of urease A and $\mathrm{B}$ genes and comparison with ribosomal RNA gene patterns. FEMS Microbiol Lett 1993; 110: 37-43

21. Pettersson F, Jönsson K-Ä, Franzèn L, Borch K. Prevalence of gastritis and Helicobacter pylori infection in a randomly selected cohort of the general population aged 35-85 years in Sweden. Abstracts, Nordic Pathology Conference 1996; Kalmar, Sweden.

22. Price AB. The Sydney System: Histological division. $J$ Gastroenterol Hepatol 1991; 6: 209-222.

23. Dixon MF, Genta RM, Yardley JH, Correa $P$, and the participants in the International Workshop on the Histopathology of Gastritis, Houston 1994. Classification and grading of gastritis. The updated Sydney System. Am J Surg Pathol 1996; 20: $1161-1181$

24. Ma J-Y, Borch K, Sjöstrand SE, Janzon L, Mårdh S. Positive correlation between $\mathrm{H}, \mathrm{K}$-Adenosine triphosphatase autoantibodies and Helicobacter pylori antibodies in patients with pernicious anemia. Scand J Gastroenterol 1994; 29: 961-965.

25. Gray MW, Sankoff D, Cedergren RJ. On the evolutionary descent of organisms and organelles: a global phylogeny based on a highly conserved structural core in small subunit ribosomal RNA. Nucleic Acids Res 1984; 12: 5837-5852.

26. Eckloff BW, Podzorski RP, Kline BC, Cockerill FR. A comparison of $16 \mathrm{~S}$ ribosomal DNA sequences from five isolates of Helicobacter pylori. Int J Syst Bacteriol 1994; 44: $320-323$.

27. Cover TL, Blaser MJ. Helicobacter pylori: a bacterial cause of gastritis, peptic ulcer disease, and gastritis. ASM News 1995; 61: $21-26$.

28. Hilali F, Saulnier P, Chachaty E, Andremont A. Decontamination of polymerase chain reaction reagents for detection of low concentrations of 16S rRNA genes. Mol Biotechnol 1997; 7: 207-216.

29. Kabir AMA, Aiba Y, Takagi A, Kamiya S, Miwa T, Koga Y. Prevention of Helicobacter pylori infection by lactobacilli in a 
gnotobiotic murine model. Gut 1997; 41: 49-55.

30. Sellner LN, Coelen RJ, Mackenzie JS. Reverse transcriptase inhibits Taq polymerase activity. Nucleic Acids Res 1992; 20: 1487-1490.

31. Miehlke S, Kibler K, Kim JG et al. Allelic variation in the cagA gene of Helicobacter pylori obtained from Korea compared to the United States. Am J Gastroenterol 1996; 91: $1322-1325$.

32. Telford JL, Ghiara P, Dell'Orco $M$ et al. Gene structure of the Helicobacter pylori cytotoxin and evidence of its key role in gastric disease. J Exp Med 1994; 179: 1653-1658.

33. Atherton JC, Cao P, Peek RM, Tummuru MKR, Blaser MJ, Cover TL. Mosaicism in vacuolating cytotoxin alleles of Helicobacter pylori. Association of specific vacA types with cytotoxin production and peptic ulceration. J Biol Chem 1995; 270: $17771-17777$.

34. Tsuda M, Karita M, Morshed MG, Okita K, Nakazawa T. A urease-negative mutant of Helicobacter pylori constructed by allelic exchange mutagenesis lacks the ability to colonize the nude mouse stomach. Infect Immun 1994; 62: 3586-3589.

35. Shen Z, Fox JG, Dewhirst FE et al. Helicobacter rodentium $\mathrm{sp}$ nov, a urease-negative Helicobacter species isolated from laboratory mice. Int $J$ Syst Bacteriol 1997; 47: 627-634.

36. McLaren A, Cox DM, Snowden MA. Isolation and characterization of urease-negative variants of Helicobacter pylori. Rev Esp Enferm Apar Dig 1990; 78: 29.

37. Pérez-Pérez GI, Olivares AZ, Cover TL, Blaser MJ. Characteristics of Helicobacter pylori variants selected for urease deficiency. Infect Immun 1992; 60: 3658-3663.

38. Blaser MJ. Not all Helicobacter pylori strains are created equal: should all be eliminated? Lancet 1997; 349: 1020-1022.

39. Fox GE, Wisotzkey JD, Jurtshuk P. How close is close: $16 \mathrm{~S}$ rRNA sequence identity may not be sufficient to guarantee species identity. Int $J$ Syst Bacteriol 1992; 42: 166-170. 